\title{
Strength analysis and modeling of cellular lattice structures manufactured using selective laser melting for tooling applications
}

Mahshid, Rasoul; Hansen, Hans Nørgaard; Loft Højbjerre, Klaus

Published in:

Materials \& Design

Link to article, DOI:

10.1016/j.matdes.2016.05.020

Publication date:

2016

Document Version

Peer reviewed version

Link back to DTU Orbit

Citation (APA):

Mahshid, R., Hansen, H. N., \& Loft Højbjerre, K. (2016). Strength analysis and modeling of cellular lattice

structures manufactured using selective laser melting for tooling applications. Materials \& Design, 104, $276-283$. https://doi.org/10.1016/j.matdes.2016.05.020

\section{General rights}

Copyright and moral rights for the publications made accessible in the public portal are retained by the authors and/or other copyright owners and it is a condition of accessing publications that users recognise and abide by the legal requirements associated with these rights.

- Users may download and print one copy of any publication from the public portal for the purpose of private study or research.

- You may not further distribute the material or use it for any profit-making activity or commercial gain

- You may freely distribute the URL identifying the publication in the public portal 


\section{Accepted Manuscript}

Strength analysis and modeling of cellular lattice structures manufactured using selective laser melting for tooling applications

Rasoul Mahshid, Hans Nørgaard Hansen, Klaus Loft Højbjerre

PII: $\quad$ S0264-1275(16)30611-6

DOI: $\quad$ doi: $10.1016 /$ j.matdes.2016.05.020

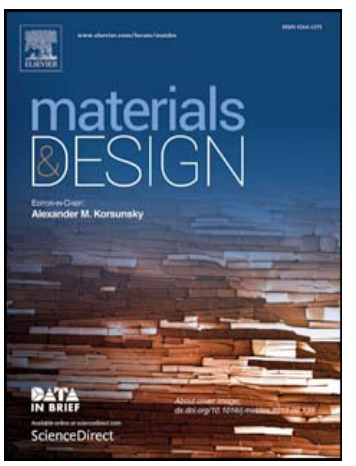

Reference: JMADE 1768

To appear in:

Received date: $\quad 12$ February 2016

Revised date: $\quad 25$ April 2016

Accepted date: 6 May 2016

Please cite this article as: Rasoul Mahshid, Hans Nørgaard Hansen, Klaus Loft Højbjerre, Strength analysis and modeling of cellular lattice structures manufactured using selective laser melting for tooling applications, (2016), doi: 10.1016/j.matdes.2016.05.020

This is a PDF file of an unedited manuscript that has been accepted for publication. As a service to our customers we are providing this early version of the manuscript. The manuscript will undergo copyediting, typesetting, and review of the resulting proof before it is published in its final form. Please note that during the production process errors may be discovered which could affect the content, and all legal disclaimers that apply to the journal pertain. 


\title{
Strength analysis and modeling of cellular lattice structures manufactured using selective laser melting for tooling applications
}

\author{
Rasoul Mahshid ${ }^{\mathrm{a}, *}$, Hans Nørgaard Hansen ${ }^{\mathrm{a}}$, Klaus Loft Højbjerre ${ }^{\mathrm{b}}$ \\ ${ }^{a}$ Technical University of Denmark, Department of Mechanical Engineering, Lyngby, \\ Denmark \\ ${ }^{b}$ Formerly at Danish Technological Institute, Aarhus, Denmark, currently at 3D-Opt ApS, \\ Copenhagen, Denmark
}

\begin{abstract}
Additive manufacturing is rapidly developing and gaining popularity for direct metal fabrication systems like selective laser melting (SLM). The technology has shown significant improvement for high-quality fabrication of lightweight design-efficient structures such as conformal cooling channels in injection molding tools and lattice structures. This research examines the effect of cellular lattice structures on the strength of workpieces additively manufactured from ultra high-strength steel powder. Two commercial SLM machines are used to fabricate cellular samples based on four architectures - solid, hollow, lattice structure and rotated lattice structure. Compression test is applied to the specimens while they are deformed. The analytical approach includes finite element (FE), geometrical and mathematical models for prediction of collapse strength - The results from the the models are verified with experimental data and it is shown that they agree well. The results from this research show that using lattice structures significantly reduces the strength of material with respect to solid samples while indicating no serious increase of strength compared to hollow structures. In combination with an analysis of microstructures, a description of strength analysis is obtained with respect to process parameters.
\end{abstract}

Keywords: additive manufacturing, selective laser melting, lattice structure, compression test, tooling application, finite element, microstructure

\section{Introduction}

Additive manufacturing has been considered a breakthrough in production systems and looked as a renaissance in manufacturing [1]. Recently, ASTM International has recommended to adopt the term additive manufacturing (AM) [2].

\footnotetext{
* Corresponding author

Email address: ramah@mek.dtu.dk (Rasoul Mahshid)
} 
This defines AM as a process of joining materials to make objects from 3D model data, usually layer upon layer. Early developments in AM focused on complex polymer-based prototypes known as rapid prototyping. With the rapid developments, AM was introduced for tooling applications (rapid tooling) such as injection molding and forming tools [3]. More advances in laser-based additive solid freeform manufacturing processes posed the possibility of layer-by-layer fabrication of complex metal components where they are impossible to achieve by conventional processes. Two powder-based melting methods, known as electron beam melting (EBM) and laser beam melting (LBM); have been introduced where powder particles are selectively melted by the scanned electron and laser beam respectively.

Using material in the parts where it is needed is the basic concept for optimum cellular lattice structures. The cellular structures have several benefits for advanced lightweight engineering applications (e.g. aircraft fuselage, wings and biomedical implants). These structures offer unique thermal and mechanical properties such as high strength-to-weight ratio, high-energy absorption, and low heat conductivity. Depending on the complexity of the part, traditional ways of manufacturing of highly porous cellular metals are limited in terms of cell size and sometimes impossible for cellular lattice structures with respect to additive manufacturing technology [4]. Selective laser melting (SLM) systems are extremely versatile and allows complex metallic cellular structures to be fabricated while positioning the cells at specific locations throughout of the part. New advances in material development enabled manufacture of metallic parts by SLM procedure from ultra-high strength steels in powder form, which is ideal for tooling applications such as punching and injection molding [5]. Therefore, if an alternative to manufacture of tools can be developed using cellular-latticestructured concept and AM to reach a lightweight structure, there is the potential to significantly improve tooling efficiency by decreasing both the material and manufacturing cost. Furthermore, achieving this goal decreases the production time of workpieces produced by the molds in high-speed applications such as micro cold forming $[6,7]$ due to the lighter tooling system causing lower maintenance due to longer tools' lifetime .

Beginning in the late 2000s, researchers began investigating how latticestructured materials affect the mechanical properties of metallic cellular solids [8]. As this research has progressed, it has been found that a vast number of material characteristics such as density, mechanical, thermal, electrical and acoustic properties can be altered using cellular structures (metal foams) while offering lightweight and sometimes cheap structures [9]. Traditionally, foams are a particular subset of lattice-structured materials. Predictability and reproducibility of mechanical properties are the big pros of metallic lattice structures [10]. In 1997, Ashby discovered that the strut-bending as the dominant mode of deformation lowers the stiffness and strength of lattice structures [11]. Deshpande et al. published a document demonstrating that stretching-governed octet-truss lattice material increases the stiffness and strength by a factor between 3 and 10 when comparing to the corresponding values for metallic foams [12]. Mines discussed on the multi-axial crush behavior of various foams and micro-lattice 
structures aiming to develop analytical and finite element models to simulate the progressive collapse of core materials used in sandwich construction [13]. From studies conducted by McKown [14], it was shown that mechanical properties of metallic open-cell lattice structures consisting of BCC and BCC,Z cubic-shaped unit-cell geometries are close to the theoretical optimum limits of open-cell foam model, described by Ashby et al. [9]. It was also discovered that using z rods in the BCC-Z unit-cell, the resistance increased in compression test to a great extent than it is possible by octahedral cells. Moreover, Tsopanos et al. showed a linear relationship between mechanical properties and combination of manufacturing parameters of laser power and laser exposure time for manufacturing of open-cell structures using BCC unit-cell [15]. Gorny et al. reported on the effects that local strain concentration, process-induced pores and the microstructure had on failure behavior of the TiAl6V4 BCC unit-cell lattice structure [16]. In 2012, Yan et al. investigated the effect of gyroid unit-cell type on the manufacturability, density and mechanical properties using compression test, microcomputer tomography and Scanning Electron Microscopy (SEM) [17]. Additionally, Smith et al. explored compressive response of lattice structures consisting of BCC and BCC-Z unit-cell shapes using finite element method when varying both the relative density and the aspect ratio of the unit cell [18]. They also reported on a reverse engineering approach for estimation of the effective strut diameter of the lattices due to the the variation of the dimensions and struts diameter along their length caused by the nature of SLM procedure. Gümrük et al. developed theoretical, experimental and numerical analyses for stainless steel micro lattice structures using Timoshenko beam model, systematic compression test and 3D finite element analyses respectively [19]. In 2014, Karamooz Ravari et al. reported on the effect the variation of the struts' diameter had on elastic modulus and collapse stress of cellular lattice structures using FE modeling [20]. While the study by Yan et al. showed possibility of manufacturing the lattice structure with struts with an angle 0 compared to the building plane as the worst building orientation for SLM [21], the study by Wauthle et al. found that horizontal struts include lots of porosities causing early failure of the structure [22].

Regarding material development for tooling applications, previous studies have indicated the ability of SLM systems to fabricate parts from tool steels such as M2 and H13 [23, 24]. The high strength tool steels in fine powder form have been tested and some are commercially available in the market [25].

Lattice materials are an array of cells making up of struts while connecting between two nodes each rigidly bonded or pin-jointed. Either the cell face can end up with solid or void leading to closed-cell or open-cell lattice structures while excluding walls of cells. Therefore, the lattice structure is comprised of a web of struts or a solid shell around the web. The material, cell shape and relative density $\rho / \rho_{s}$ (where $\rho$ and $\rho_{s}$ are the density of cellular material and the solid respectively) are the key process parameters determining properties of cellular materials. The purpose of these materials is to make stiff structures using unit cells where they are useful such that the new material is as light as possible. By doing so, the strength and stiffness of the material becomes weaker, when the 
amount of material required to fabricate the part is reduced. The second goal of the cellular structures is to increase maximum achievable functionality of the component of which the lattice used such as energy absorption, large strain, stiffness and strength.

The main aim of this study is to obtain an insight into using cellular lattice structures for high performance bear loading constructions such as mold components when compared to solid and hollow structures. The solid structure represents the conventional way of tool construction when hollow sample determines the state of structure with no cellular lattices. The current research involves methods for strength analysis of structures additively manufactured in order to maximize the strength and minimize the weight of the components to be utilized in tooling applications, thereby reducing both the manufacturing time and material cost of tools. More specifically, the research examines how the cellular lattices increase the efficiency of the tooling structures when applying compression load. To examine this possibility, it is important to design a combination of structures for specimens (four architectures will be examined as part of this study). A further purpose of this research is to model accurately the collapse strength of hollow and cellular lattice structures manufactured using SLM under compression load. FE, geometrical and mathematical models are used and analytical predictions are compared to experimental tests.

\section{Material and methods}

\subsection{Lattice structures}

In a study conducted by Rehme and Emmelmann, the effect of uniaxial compressive test on cellular structures with eight different cell types was investigated [26]. This research involved finding optimal unit cell type in order to maximize the collapse strength and minimize the overall achievable density. A cell type named $\mathrm{F}_{2} \mathrm{CC}-\mathrm{Z}$ got the best ratio for collapse strength-to-density. This unit cell consisted of rods in vertical direction and double-faced diagonals as shown in Figure 1. As previously mentioned, the presence of vertical struts enhances the strength of lattice structure [14]. In subsequent studies, it was discovered that the orientation of single struts along the flux of force prevents unwanted bending loads on the lattice structure, thereby appearing only push and pull force in the structure [27]. To increase the strength of testing structures in $\mathrm{z}$ direction, the unit cell $\mathrm{F}_{2} \mathrm{CC}-\mathrm{Z}$ was modified in order to maximize the number of $\mathrm{z}$ rods with five vertical and eight body-centered rods in this research (Figure 1). Similar unit cell shape was used to model the behavior of plastic lattice structures manufactured using fused deposition modeling under compression load [20].

\subsection{Experimental setup}

The samples used in this study are cylinders of $28 \mathrm{~mm}$ diameter and $46 \mathrm{~mm}$ height. The lattice structure is created by cubic unit cells with the edge length of $4 \mathrm{~mm}$ and strut diameter of $0.73 \mathrm{~mm}$. In order to determine more exactly 


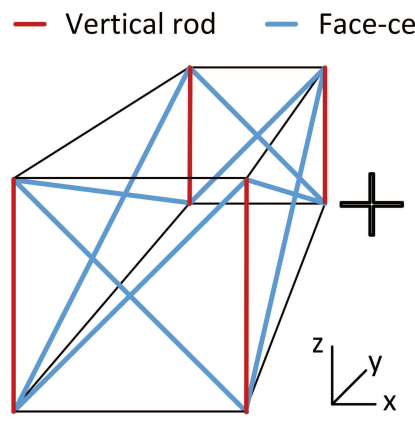

$\mathrm{F}_{2} \mathrm{CC}, \mathrm{Z}$

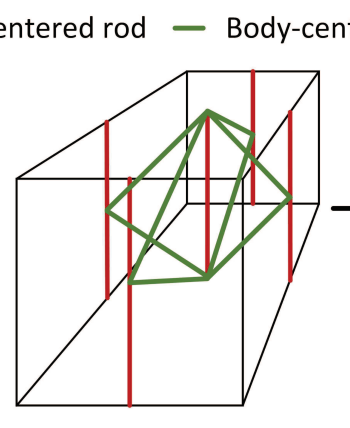

Modifications

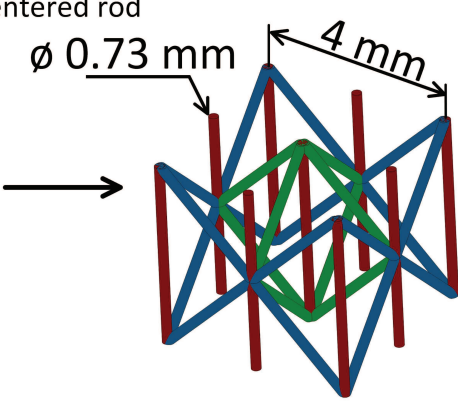

Unit cell shape

Figure 1: Fundamental design for development of the unit cell

the effect of lattice structures on strength, four combinations of specimens were examined, as shown in Figure 2. This includes solid, hollow, closed-cell nonrotated (ST) and closed-cell rotation of $30^{\circ}$ (ST-30) samples. Tools generally include several features (depending on the application) such as holes for punch holders, tool inserts, contours and cooling channels. Therefore, the cellular and hollow samples have a wall thickness of $5 \mathrm{~mm}$ in all sides.

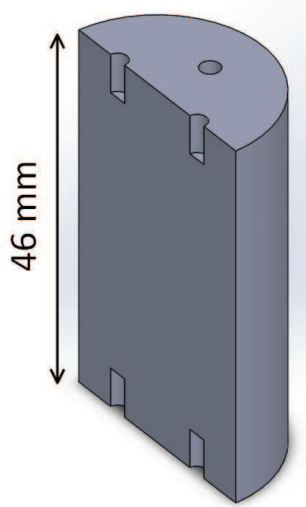

Solid

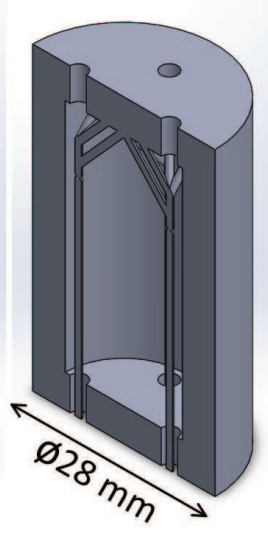

Hollow

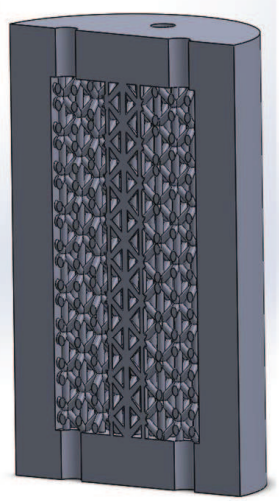

ST

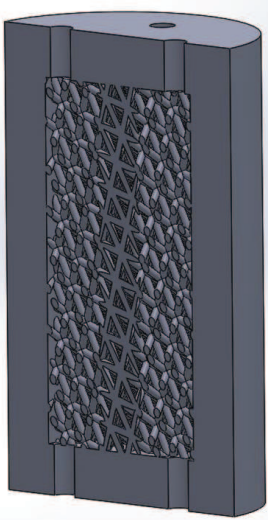

ST-30

Figure 2: Structure combination of samples (cross-section)

Two commercial SLM systems (called Laser 1 and Laser 2 in this research) produced the same combination of the samples using process parameters listed in Table 1. To verify the repeatability of the results, three specimens were tested for each sample structure/SLM system combinations. In total, 12 samples were manufactured by each SLM machines for the tests.

Four small holes on the bases indicate the exits for depowdering phase of 
Table 1: Process parameters of SLM machines

\begin{tabular}{lcc}
\hline & Laser 1 & Laser 2 \\
\hline Scanning strategy & Bidirectional & Bidirectional \\
Power $(W)$ & 180 & 195 \\
Hatching spacing $(\mu \mathrm{m})$ & 150 & 100 \\
Scanning speed $(\mathrm{mm} / \mathrm{s})$ & 600 & 750 \\
Layer thickness $(\mu \mathrm{m})$ & 30 & 40 \\
\hline
\end{tabular}

the manufacturing process. The four straight rods inside the hollow samples (Figure 2) were required to support the "roof" of the cylinder since surfaces with an angle less than 45 degrees compared to horizontal require support in one way or another $[28,29]$. The 4 rods were designed such that they could be broken off before compression test and only leave the struts beneath the roof which it would only cause a minor contribution to the compression strength. To reduce the effect of material variability, both SLM systems used two alloys with the same chemical composition (DIN:1.2709). Table 2 lists the alloys and testing conditions, along with the examined structure/relative density. Laser 1 and Laser 2 are two laser-based SLM systems commercially available for direct melting and sintering of metal powders. The material is hot work steel corresponding to 1.2709 for all samples. This came from CL50WS in Laser 1 and MS1 (Maraging Steel) in Laser 2. The two materials are initially in fine powder form.

Table 2: Experimental alloys and testing conditions

\begin{tabular}{lccc}
\hline $\begin{array}{l}\text { SLM system } \\
\text { (Material) }\end{array}$ & Structure & $\begin{array}{c}\text { Relative } \\
\text { density }\end{array}$ & $\begin{array}{c}\text { Number of } \\
\text { tests }\end{array}$ \\
\hline Laser 1 & Solid & 1 & 3 \\
(CL50WS) & Hollow & 0.7 & 3 \\
& ST & 0.8 & 3 \\
& ST-30 & 0.8 & 3 \\
\hline Laser 2 & Solid & 1 & 3 \\
(MS1) & Hollow & 0.7 & 3 \\
& ST & 0.8 & 3 \\
& ST-30 & 0.8 & 3 \\
\hline
\end{tabular}

Subsequent to performing 3D-printing process, the samples were heat-treated by age hardening. Glass blasting performed on all sides of samples in order to remove any unintentional effects from the heat-treatment. Then the specimens were ground on both bases. When grinding the samples for compression test, it is important to maintain tight tolerances on parallelism of the two bases and perpendicularity of the bases to the side. For hardness testing, a calibrated OTTO Wolpert-WERKE GMBA Hardness Tester was used on the ground surfaces and 
four measurements were replicated for each testing sample. All samples showed a hardness in the range of 52-54 Rc after heat-treatment. One specimen of each structure were cut by wire-EDM to observe possible manufacturing defects, as shown in Figure 3 for reference.

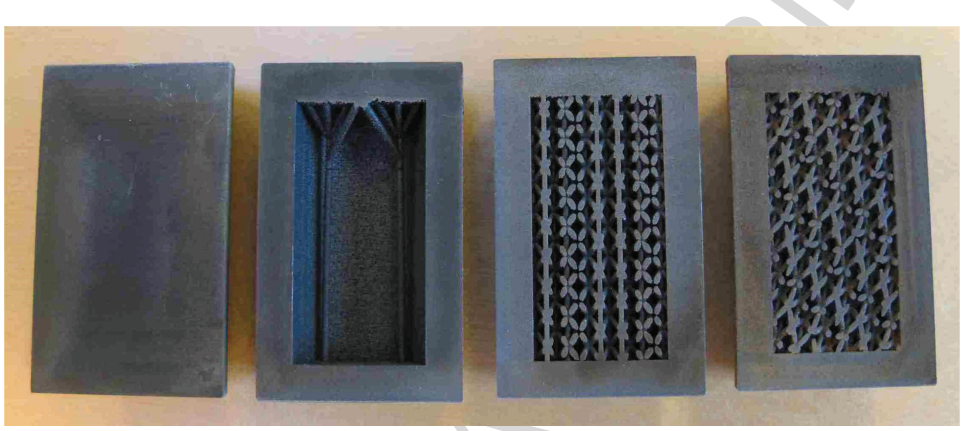

Figure 3: Specimens manufactured using SLM systems (Solid, Hollow, ST, ST-30)

In order to determine the flow stress curve, common compression test was conducted. The cylindrical specimens exhibit length to diameter ratio $\left(l_{0} / d_{0}\right)$ of 1.6 [30]. For compression testing described herein, an Instron 8508 Servohydraulic $5 \mathrm{MN}$ Testing Machine was used. The samples are squeezed between two hardened platens mounted on the upper and lower beds of the machine. The frictional condition is under dry condition when no lubricant is applied in the interfaces between the workpiece and the forming tools. To observe real time displacement of the plates, three inductive displacement transducers continuously monitored and captured the position at 10-millisecond time intervals while force measurements relies on a built-in facility of the machine. This setup is shown in Figure 4.

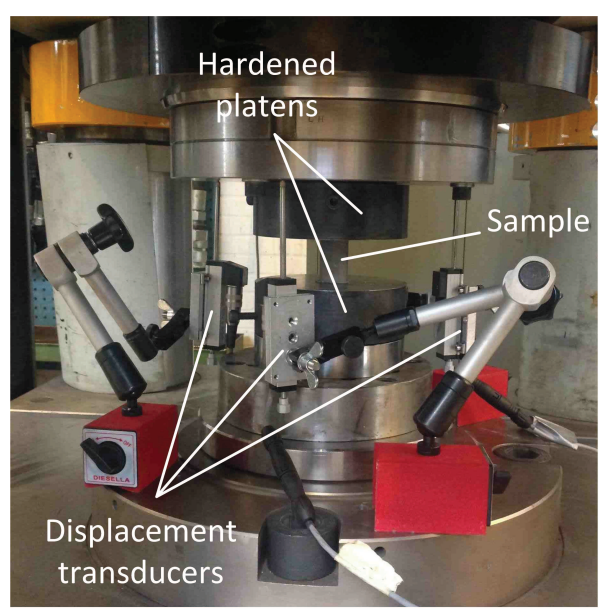

Figure 4: Experimental setup 
A PC-based software was used to control the Instron Testing Machine and to capture force vs. position data throughout each test. In addition, the strain rate has the initial value of $1 \mathrm{~mm} / \mathrm{min}$. in this study. Due to the presence of barreling, displacement (contraction) was used instead of strain since the assumption of uniform straining within the entire test region of the specimen exists no longer in the tests [31].

To provide a means of establishing structures effect, the tests of solid samples were examined for baseline test. While three tests were run for each sample conditions, to ease the ability of visualization, only the average curves are used. Thus, each plot only contains three sample tests (hollow, ST and ST-30) and their respective baseline test.

\subsection{Numerical modeling}

Three-dimensional flow of the deformation process in the compression test was performed using DEFORM-3D simulation system based on the finite element method. four-node tetrahedral element was used to generate mesh on the 3D model while applying force by two 3D rigid plates on the top and bottom surface of the cylinder. Tetrahedral element was used to ease meshing complex geometry of lattices at the joints where the struts are connected. A rigid plate (bottom die) is fixed when the top die moves in $-z$ direction to squeeze the workpiece. Rigid objects are modeled as non-deformable materials to increase simulation speed (over elastic tooling). The modeling of rigid bodies has a built-in algorithm in the package when the geometry profile is just required. The contact properties were set to shear friction for the nodes at the top and bottom surfaces of the workepiece where the translational moves have no constraint. The contact nodes are established to keep the rigid plates and workpiece from penetrating each other. The material behavior is elastic-plastic and based on CL50WS. The data recorded for deformation of the solid samples in the compression test has the role of reference and was used to calibrate the FEA of solid workpiece. The stress-strain curve computed from experimental data of solid initially was used as the input data for the FEA of solid and the output from the analysis was compared to experimental force-displacement curve. The friction constant then varied until both the experimental and FE force-displacement have the best fit. The friction coefficient of 1.5 was found when the fitness of calibration curve achieved the accuracy of $\pm 1 M P a$ at the collapse strength point with respect to the experimental data.

\section{Results}

In this section, the first part considers the compressive response of the structures obtained from the experiments. The next three parts include three analytical models for prediction of the collapse strength of the structures while the modeling results are compared to experimental data. In the last part, microstructure of the samples is analyzed with respect to process parameters of the SLM machines. 
To improve the ability to interpret the effect of the structure on material strength, the engineering stress-displacement curves are plotted for each group of samples while showing the curve of solid sample as the baseline. It is important to note that when computing the engineering stress (for all subsequent curves), the cross-section of solid sample is used. In order to exactly determine the collapse strength, fitting a least-squares linear regression line is employed along with the offset method (\%0.02) according to ASTM standard [32].

\subsection{Compressive response}

The deformation of samples and lattice structures in the compression test is shown for a representative specimen of each combination in Figure 5. When performing compression test, while shortening the height of samples up to 5 $\mathrm{mm}$, the barreling effect is observed in the compressed specimens. The flow stress curves of samples associated with Laser 1 and Laser 2 systems when deformed while applying the compression uniaxial force are shown in Figure 6a and Figure $6 \mathrm{~b}$ respectively.

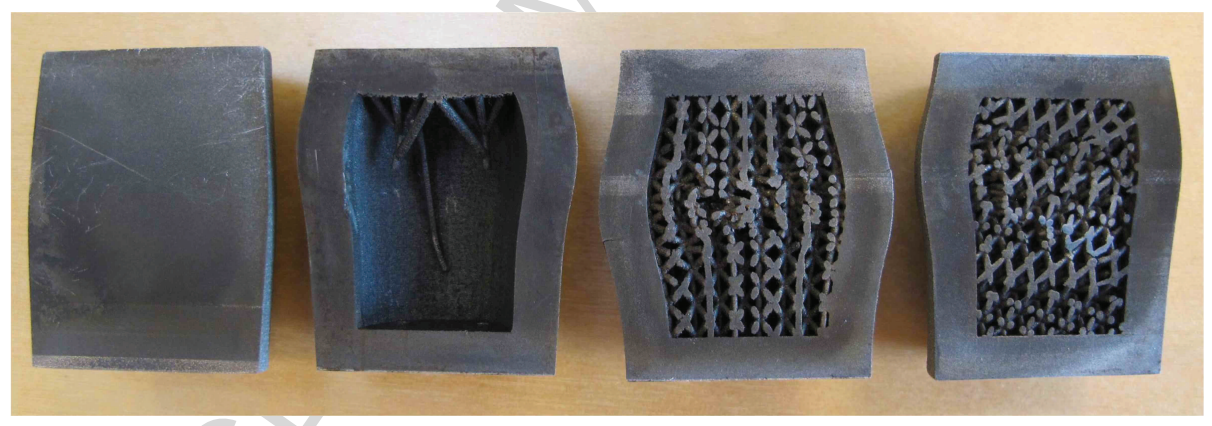

Figure 5: Deformation of samples in compression test

The compression strength is the significant parameter obtained from the curves, since the main purpose of the structures is to be utilized in tooling application and the plastic deformation has no benefit for tools. Therefore, the average yield stresses derived from the curves along with one standard deviation at this point are listed in Table 3 for Laser 1 and Laser 2.

When comparing the average yield stress of the baseline (1693.3 MPa) while applying the conditions associated with Laser 1 to the average engineering stress of respective hollow samples (927.6 MPa) a decrease of $45.2 \%$ is observed (Table 3 ). In addition, the yield stress also decreased $37.8 \%$ with respect to the solid samples for ST structures, due to the reduction of relative density. The tests also showed reduction of $37.1 \%$ for ST-30 samples. To this end, latticestructured samples result in the average flow stress that is only $7.4 \%$ higher (1053.2 MPa) than hollow material while showing the same strength for ST and ST-30.

Likewise, when applying the conditions associated with Laser 2 system, a similar pattern for material behavior was also observed. While using Laser 2, 


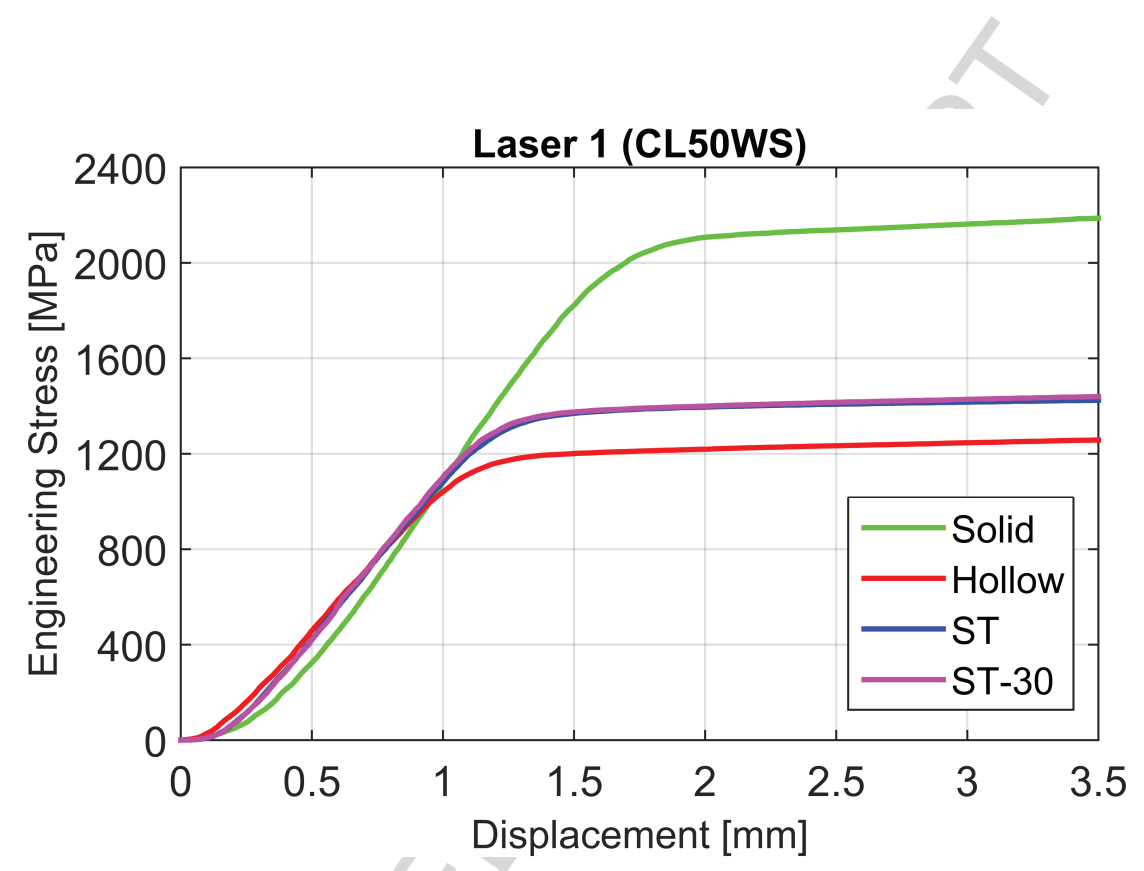

(a)

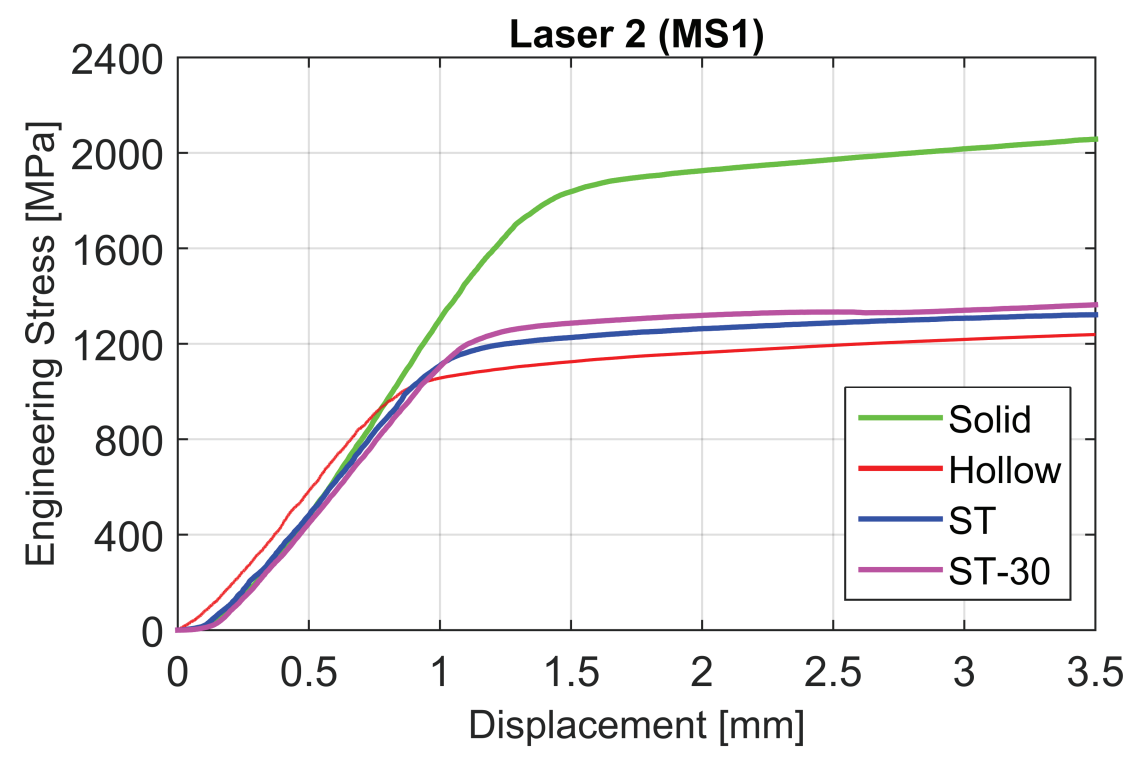

(b)

Figure 6: The engineering stress-displacement curves 
Table 3: Reduction of the collapse strength

\begin{tabular}{ccc}
\hline SLM & Structure & $\begin{array}{c}\text { Collapse strength } \\
\text { (MPa) }\end{array}$ \\
\hline \multirow{4}{*}{ Laser 1 } & Solid & $1693.3 \pm 120.4$ \\
& Hollow & $927.6 \pm 26.2$ \\
& ST & $1053.2 \pm 24.7$ \\
& ST-30 & $1064.4 \pm 34.2$ \\
\hline \multirow{3}{*}{ Laser 2 } & Solid & $1566.0 \pm 55.9$ \\
& Hollow & $844.6 \pm 0.3$ \\
& ST & $1024.5 \pm 16.0$ \\
& ST-30 & $1059.8 \pm 14.5$ \\
\hline
\end{tabular}

the yield stress had maximum reduction at hollow samples when compared to Laser 1; yielding the average yield stress of $844.6 \mathrm{MPa}$, equivalent to $8.9 \%$ overall reduction with respect to Laser 1 . This reductions were $7.5 \%$ and $2.7 \%$ for solid and ST with respect to Laser 1, while detected almost no reduction for ST-30. In addition, when applying the conditions associated with Laser 2, the yield stress was lowered to the same extent as occurred for samples manufactured under the conditions of Laser 1. The reductions were $46.0 \%, 34.6 \%$ and $32.3 \%$ in comparison with the respective baseline for hollow, ST and ST-30 samples respectively (Table 3 ).

In examining the graphs, significant reduction of the strength is found to exist for hollow and lattice structures. An additional observation regarding the structure event is that, while the yield stress reduced approximately $60 \%$, the new structures have more lightweight efficiency when using in applications with lower stress than collapse strength of hollow or ST samples.

\subsection{FE analysis}

To provide a more detailed analysis of the structures effect on specimens strength, cold forming analysis of the hollow and ST samples was also conducted by FEA. The graphs of engineering stress versus displacement are depicted in Figure 7. In examining the diagrams, variability was found to exist between the simulation and experiment especially for hollow and ST specimens at the elastic region due to variation of dimensions of the specimens caused by the nature of manufacturing process when nominal values were used at $\mathrm{FE}$ analysis. However, this variability was deemed negligible for the purpose of estimation of the yield stress. The graph also reveals that the FEA obtained sufficient results for strength analysis. From data analysis, the yield stresses were found as listed in Table 4 . The analysis clearly shows the reduction of yield stress corresponding to $46.2 \%$ and $41.0 \%$ for hollow and ST samples respectively.

To evaluate the mesh quality of simulations, mesh-sensitivity analysis was performed on the structures to realize the effect of element size on the collapse strength. The minimum element size was refined for each structure. Table 5 


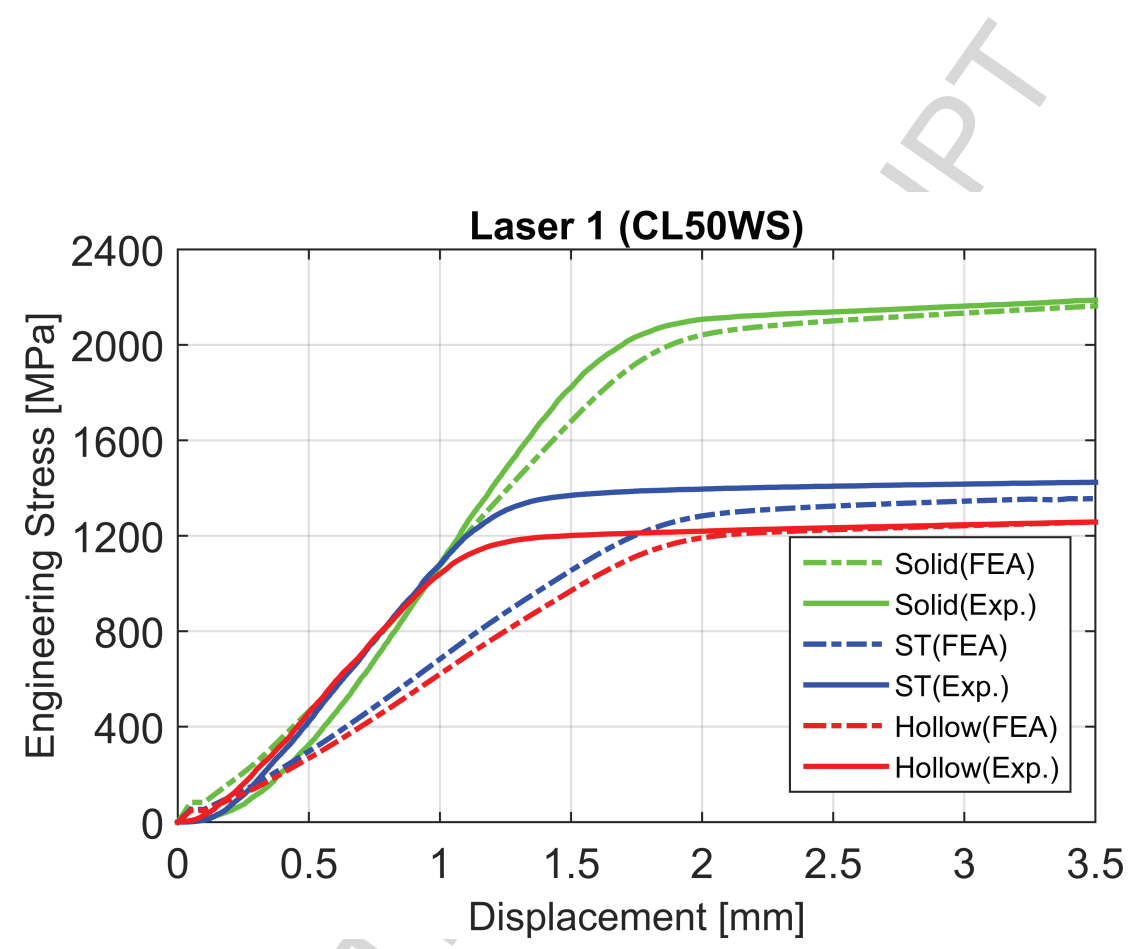

Figure 7: FEA of compression test for solid, hollow and ST samples

Table 4: Yield stresses obtained from FEA and experiment $(M P a)$

\begin{tabular}{lcc}
\hline Structure & Experiment & FEA \\
\hline Solid & $1693.3 \pm 120.4$ & 1678.6 \\
Hollow & $927.6 \pm 26.2$ & 903.9 \\
ST & $1053.2 \pm 24.7$ & 990.1 \\
ST-30 & $1064.4 \pm 34.2$ & N/A \\
\hline
\end{tabular}


presents the mesh size and respective collapse strength. It is apparent that increasing the mesh density further produced only small changes in collapse strength. For a quarter of ST structure, an increase from 174686 elements (Mesh size: $0.28 \mathrm{~mm}$ ) to 315384 elements (Mesh size: 0.22 ) yields only $3.7 \mathrm{MPa}$ increase in collapse stress. Therefore, no variation was detected by refining the mesh density.

Table 5: Mesh-sensitivity analysis for three minimum element sizes

\begin{tabular}{lcccccc}
\hline Structure & \multicolumn{3}{l}{ Min. } & mesh size $(\mathrm{mm})$ & \multicolumn{4}{c}{ Collapse strength $(\mathrm{MPa})$} \\
\hline Solid & 0.37 & 0.3 & 0.25 & 1679 & 1678 & 1679 \\
Hollow & 0.45 & 0.4 & 0.3 & 903.9 & 902.3 & 902.8 \\
ST & 0.28 & 0.25 & 0.22 & 990.1 & 993.8 & 993.1 \\
\hline
\end{tabular}

\subsection{Minimum cross-section}

However, meshing procedure and simulation of the 3D lattice structures are highly time-consuming when increasing the number of cells. The effective stress contour for $2 \mathrm{~mm}$ compression of the specimen is shown in Figure 8. As can be seen, the plot shows significant stress in vertical rods and sidewalls compared to the body-centered and face-centered rods (Figure 1). One possible reason for this is that, since the specimens stress was considerably increased along force flux (z-axis), the minimal real cross-section area at the same direction may have been more beneficial than the other parameters.

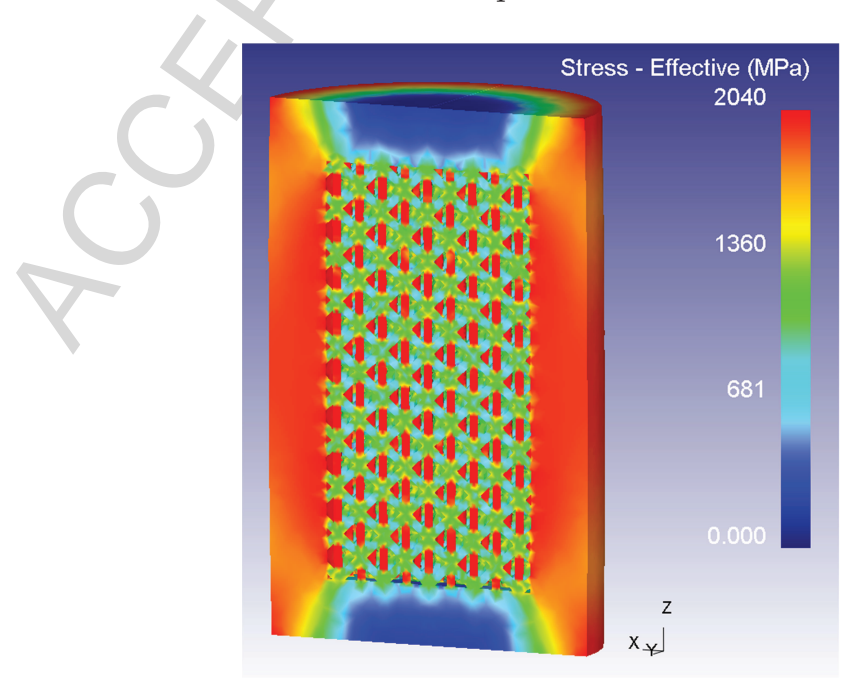

Figure 8: Stress contour for $2 \mathrm{~mm}$ displacement

More specifically, the minimum real cross-section area may have caused premature failure of the specimen due to highly localized stress within a narrowed 
region. Therefore, the cross-section areas were measured exactly using a macro for CAD models shown in Figure 2 to find the minimum cross-section area along the height of the samples. For the purpose of this analysis, the CAD model of samples was cut in $z$ direction in order to observe minimum cross-section area. This was 620, 360, 400 and $440 \mathrm{~mm}^{2}$ for solid, hollow, ST and ST-30 samples respectively. Consequently, with respect to the cross-section area of solid samples, the reduction of area corresponds to $41.2 \%, 35.5 \%$ and $29.0 \%$ for hollow, ST and ST-30. By comparing the results from this method and compression tests, it becomes apparent that percent decrease of critical cross-section area is an effective method to foresee the strength of the cellular structures used in this research.

\subsection{Ashby \& Gibson model}

The analytical analysis for the samples can be found from a mathematical model given for modeling metal foam properties developed by Gibson and Ashby [8]. The models are available for open-cell and closed-cell cellular parts. The samples in this research are kind of closed-cell structures, which show a behavior that is more complicated when comparing to open-cell structures when surrounding the web of strut by solid shell. For a closed-cell structure the scaling relations of compression strength is defined as:

$$
\sigma_{c}=(0.1-1.0) \sigma_{c, s} \times\left[0.5\left(\frac{\rho}{\rho_{s}}\right)^{2 / 3}+0.3\left(\frac{\rho}{\rho_{s}}\right)\right]
$$

Where symbols with a subscripted $s$ means property of the solid metal of which the structure is made. When using the information listed in ?? for relative density, the statement in the bracket of the above formula returns the value of 0.6 and 0.67 for hollow and lattice structures respectively. Since ST and ST-30 samples have the same relative density, the proposed theoretical model give the same value for both. As was proved for minimal cross-section and FEA, once again this approach indicated $40 \%$ and $33 \%$ reduction of compression strength. This method is also useful for approximate analysis of closed-cell structures in the early stages of design where needed to decide. Table 6 summarizes the results for the analytical methods and the experiments. As can be seen from the table, while the FEA has the best result for hollow structure, Min cross-section and Equation (1) yield better estimation for compression strength of ST and ST-30 samples.

\subsection{Microstructure analysis}

SLM technique is a complicated production method with respect to microstructure evolution. This occurs due to the high temperature gradients causing thermal stresses and rapid solidification. A sample manufactured by each SLM machine was sectioned (Figure 3) and mounted in epoxy to observe the microstructure. The polished samples were etched in Kalling No. 1. The micrographs of the specimens for 5X and 50X magnifications are shown in Figure 9. When viewing the micrographs, higher degree of porosity can be observed for 
Table 6: Percent reductions obtained from experiment and analysis

\begin{tabular}{lccc}
\hline Method & Hollow & ST & ST-30 \\
\hline Laser 1 & 45.2 & 37.8 & 37.1 \\
Laser 2 & 46.0 & 34.6 & 32.3 \\
FEA & 46.2 & 41.0 & $\mathrm{n} / \mathrm{a}$ \\
Min. cross-section & 42 & 35.4 & 29 \\
Equation (1) & 40 & 33 & 33 \\
\hline
\end{tabular}

Laser 2. While not shown, this was true for other regions of samples and optical images showed similar defects for samples from Laser 2 system. The dimension, density and orientation of the pore pattern is dependent on the choice of process parameters such as scanning strategy, hatching space and scanning velocity in SLM procedures [33, 34]. Generally, the pores decrease the time of crack initiation by creating highly localized stressing in the material around pores region. Therefore, the higher density of pores can be harmful to the mechanical properties. This may have been a possible reason for lower strength of samples manufactured by Laser 2 .
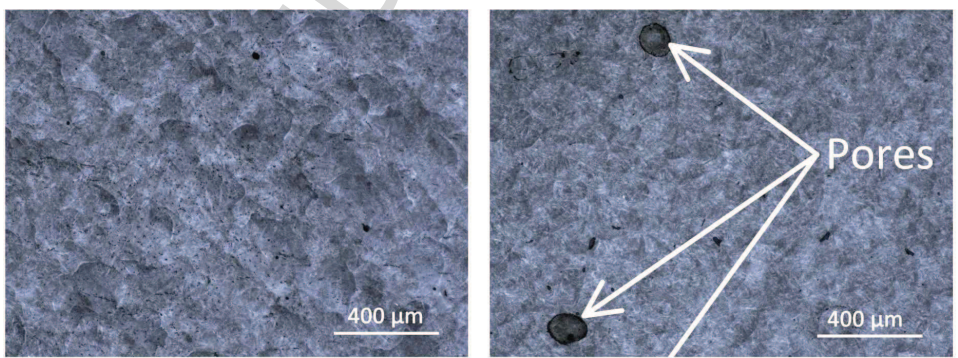

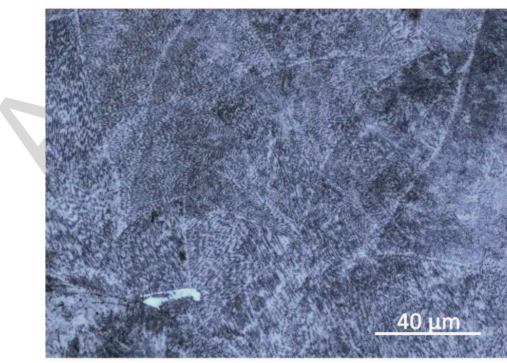

Laser 1 (CL50WS)

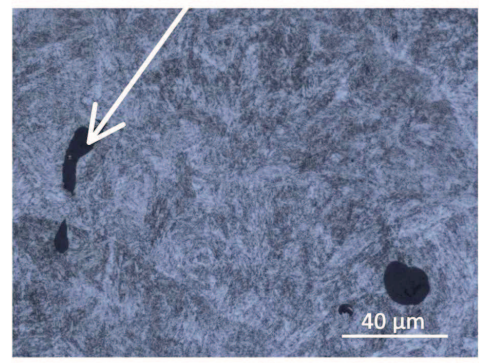

Laser 2 (MS1)

Figure 9: Optical micrographs showing voids of samples

When comparing the scanning speed of Laser 1 to Laser 2 (Table 1), an increase of $25 \%$ is observed in Laser 2. The higher scanning speed decreases the production time. However, in order to increase the quality and density, energy density of laser $\left(E\right.$ in $\left.J / \mathrm{mm}^{3}\right)$ must be optimized with respect to relative density 
[35]. The energy supplied by laser beam per volume unit of powder material is defined by:

$$
E=\frac{P}{v \times h \times t}
$$

Where $P(W)$ is the laser power, $v(\mathrm{~mm} / \mathrm{s})$ is the laser scanning speed, $h(\mathrm{~mm})$ is the hatching distance and $t(\mathrm{~mm})$ is the layer thickness. When applying the process parameters associated with Laser 1 while using Equation (2), almost the same energy density is observed in comparison to Laser 2. To achieve optimal results, unique energy density would need to be employed for each alloy/machine combination to minimize balling effects and instability of molten pool, which have been reported as undesirable phenomena during SLM. The improvement in the relative density while using Laser 2 is reduced due to the higher porosity; yielding different mechanical properties.

\section{Conclusion}

This paper has introduced a strength analysis for porous structures which have the potential of being replaced with dense materials in tooling applications. The proposed method includes compression test of the solid, hollow, nonrotated-closed-cellular and rotated-closed-cellular samples manufactured using two SLM systems. The unit cell shape is modified with vertical rods to increase maximum achievable resistance against compression loading. In comparison with solid samples, the cellular structures heavily influence the compression strength (about $60 \%$ reduction) and show only an increase of $11.4 \%$ at the highest with respect to hollow specimens for both SLM systems. The flow stress is also analyzed using three analytical models where they work the best in conjunction with the tests. Minimum cross section and Ashby \& Gibson models offer non-expensive solutions to predict collapse strength of larger cellular lattice structures when compared to FE analysis. The structures consisting of modified $\mathrm{F}_{2} \mathrm{CC}, \mathrm{Z}$ unit-cell shape depicts close mechanical properties to the theoretical limits of closed-cell metal foam model described by Ashby \& Gibson. The overall decrease of strength in samples manufactured by Laser 2 is verified with the higher pore density observed in the respective microstructure by viewing the optical micrographs.

\section{Acknowledgment}

The work was funded by the Danish Research Agency through the innovation consortium FMAT. The authors thank colleagues who provided insight and expertise that greatly assisted the research. 


\section{References}

[1] Joseph Beaman, Dave Bourell, and Darrell Wallace. Special issue: Additive manufacturing (am) and 3d printing. Journal of Manufacturing Science and Engineering, 136(6):060301, 2014.

[2] Annual Book of ASTM Standards, volume 10.04, chapter F2792-12a Standard Terminology for Additive Manufacturing Technologies,. ASTM International, PA, USA, April 2015.

[3] Dong-Gyu Ahn. Applications of laser assisted metal rapid tooling process to manufacture of molding \& forming toolsstate of the art. International Journal of Precision Engineering and Manufacturing, 12(5):925-938, 2011.

[4] P Colombo and H P Degischer. Highly porous metals and ceramics. Materials Science and Technology, 26(10):1145-1158, 2010.

[5] Fritz Klocke, Andreas Klink, Drazen Veselovac, David Keith Aspinwall, Sein Leung Soo, Michael Schmidt, Johannes Schilp, Gideon Levy, and JeanPierre Kruth. Turbomachinery component manufacture by application of electrochemical, electro-physical and photonic processes. CIRP AnnalsManufacturing Technology, 63(2):703-726, 2014.

[6] R. Mahshid, H. N. Hansen, and M. Arentoft. Characterization of precision of a handling system in high performance transfer press for micro forming. CIRP Annals - Manufacturing Technology, 63(1):497-500, 2014.

[7] Rasoul Mahshid, Hans Nørgaard Hansen, and Mogens Arentoft. Towards mass production by high performance transfer press in micro bulk forming. Procedia Engineering, 81:1445-1450, 2014.

[8] Lorna J Gibson and Michael F Ashby. Cellular solids: structure and properties. Cambridge university press, 1997.

[9] Michael F Ashby, Tony Evans, Norman A Fleck, J W Hutchinson, H N G Wadley, and L J Gibson. Metal Foams: A Design Guide: A Design Guide. Elsevier, 2000.

[10] John Banhart. Manufacture, characterisation and application of cellular metals and metal foams. Progress in materials science, 46(6):559-632, 2001.

[11] M F Ashby. The properties of foams and lattices. Philosophical Transactions of the Royal Society of London A: Mathematical, Physical and Engineering Sciences, 364(1838):15-30, 2006.

[12] Vikram S Deshpande, Norman A Fleck, and Michael F Ashby. Effective properties of the octet-truss lattice material. Journal of the Mechanics and Physics of Solids, 49(8):1747-1769, 2001.

[13] RAW Mines. On the characterisation of foam and micro-lattice materials used in sandwich construction. Strain, 44(1):71-83, 2008. 
[14] S McKown, Y Shen, W K Brookes, C J Sutcliffe, W J Cantwell, G S Langdon, G N Nurick, and M D Theobald. The quasi-static and blast loading response of lattice structures. International Journal of Impact Engineering, 35(8):795-810, 2008.

[15] S Tsopanos, R A W Mines, S McKown, Y Shen, W J Cantwell, W Brooks, and C J Sutcliffe. The influence of processing parameters on the mechanical properties of selectively laser melted stainless steel microlattice structures. Journal of Manufacturing Science and Engineering, 132(4):41011, 2010.

[16] B Gorny, T Niendorf, J Lackmann, M Thoene, T Troester, and H J Maier. In situ characterization of the deformation and failure behavior of nonstochastic porous structures processed by selective laser melting. Materials Science and Engineering: A, 528(27):7962-7967, 2011.

[17] Chunze Yan, Liang Hao, Ahmed Hussein, and David Raymont. Evaluations of cellular lattice structures manufactured using selective laser melting. International Journal of Machine Tools and Manufacture, 62:32-38, 2012.

[18] M Smith, Z Guan, and W J Cantwell. Finite element modelling of the compressive response of lattice structures manufactured using the selective laser melting technique. International Journal of Mechanical Sciences, 67:28-41, 2013.

[19] R Gümrük and RAW Mines. Compressive behaviour of stainless steel micro-lattice structures. International Journal of Mechanical Sciences, 68:125-139, 2013.

[20] MR Karamooz Ravari, M Kadkhodaei, M Badrossamay, and R Rezaei. Numerical investigation on mechanical properties of cellular lattice structures fabricated by fused deposition modeling. International Journal of Mechanical Sciences, 88:154-161, 2014.

[21] Chunze Yan, Liang Hao, Ahmed Hussein, Philippe Young, and David Raymont. Advanced lightweight 316L stainless steel cellular lattice structures fabricated via selective laser melting. Materials \&3 Design, 55:533-541, 2014.

[22] Ruben Wauthle, Bey Vrancken, Britt Beynaerts, Karl Jorissen, Jan Schrooten, Jean-Pierre Kruth, and Jan Van Humbeeck. Effects of build orientation and heat treatment on the microstructure and mechanical properties of selective laser melted Ti6Al4V lattice structures. Additive Manufacturing, 5:77-84, 2015.

[23] M Badrossamay and T H C Childs. Further studies in selective laser melting of stainless and tool steel powders. International Journal of Machine Tools and Manufacture, 47(5):779-784, 2007. 
[24] T H C Childs, C Hauser, and M Badrossamay. Selective laser sintering (melting) of stainless and tool steel powders: experiments and modelling. Proceedings of the Institution of Mechanical Engineers, Part B: Journal of Engineering Manufacture, 219(4):339-357, 2005.

[25] Jean-Pierre Kruth, Peter Mercelis, J Van Vaerenbergh, Ludo Froyen, and Marleen Rombouts. Binding mechanisms in selective laser sintering and selective laser melting. Rapid prototyping journal, 11(1):26-36, 2005.

[26] Olaf Rehme and Claus Emmelmann. Rapid manufacturing of lattice structures with selective laser melting. In Lasers and Applications in Science and Engineering, pages $61070 \mathrm{~K}-61070 \mathrm{~K}$. International Society for Optics and Photonics, 2006.

[27] G Reinhart and S Teufelhart. Optimization of mechanical loaded lattice structures by orientating their struts along the flux of force. Procedia CIRP, 12:175-180, 2013.

[28] Volker Weißmann, Rainer Bader, Harald Hansmann, and Nico Laufer. Influence of the structural orientation on the mechanical properties of selective laser melted ti6al4v open-porous scaffolds. Materials \& Design, 2016.

[29] Di Wang, Yongqiang Yang, Ruicheng Liu, Dongming Xiao, and Jianfeng Sun. Study on the designing rules and processability of porous structure based on selective laser melting (slm). Journal of Materials Processing Technology, 213(10):1734-1742, 2013.

[30] JS Gunasekera, J Havranek, and MH Littlejohn. The effect of specimen size on stress-strain behavior in compression. Journal of Engineering Materials and Technology, 104(4):274-279, 1982.

[31] Yingbing Luo, Craig Miller, George Luckey, Peter Friedman, and Yinghong Peng. On practical forming limits in superplastic forming of aluminum sheet. Journal of materials engineering and performance, 16(3):274-283, 2007.

[32] Annual Book of ASTM Standards, volume 03.01, chapter E9-09 Standard Test Methods of Compression Testing of Metallic Materials at Room Temperature. ASTM International, PA, USA, July 2015.

[33] Lore Thijs, Frederik Verhaeghe, Tom Craeghs, Jan Van Humbeeck, and Jean-Pierre Kruth. A study of the microstructural evolution during selective laser melting of Ti6Al4V. Acta Materialia, 58(9):3303-3312, 2010.

[34] Dongdong Gu, Yves-Christian Hagedorn, Wilhelm Meiners, Guangbin Meng, Rui João Santos Batista, Konrad Wissenbach, and Reinhart Poprawe. Densification behavior, microstructure evolution, and wear performance of selective laser melting processed commercially pure titanium. Acta Materialia, 60(9):3849-3860, 2012. 
[35] Hooyar Attar, Mariana Calin, LC Zhang, Sergio Scudino, and Jürgen Eckert. Manufacture by selective laser melting and mechanical behavior of commercially pure titanium. Materials Science and Engineering: A, 593:170177, 2014. 


\section{Graphical Abstract}

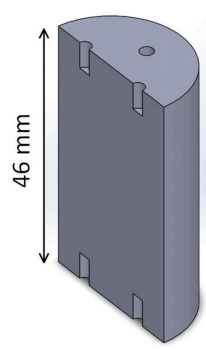

Solid

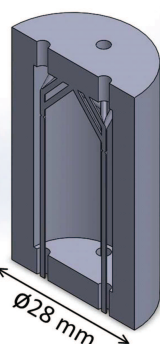

Hollow

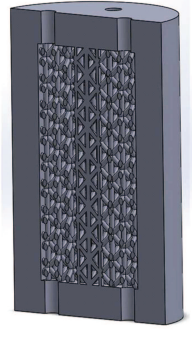

ST

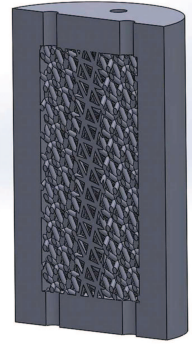

ST-30
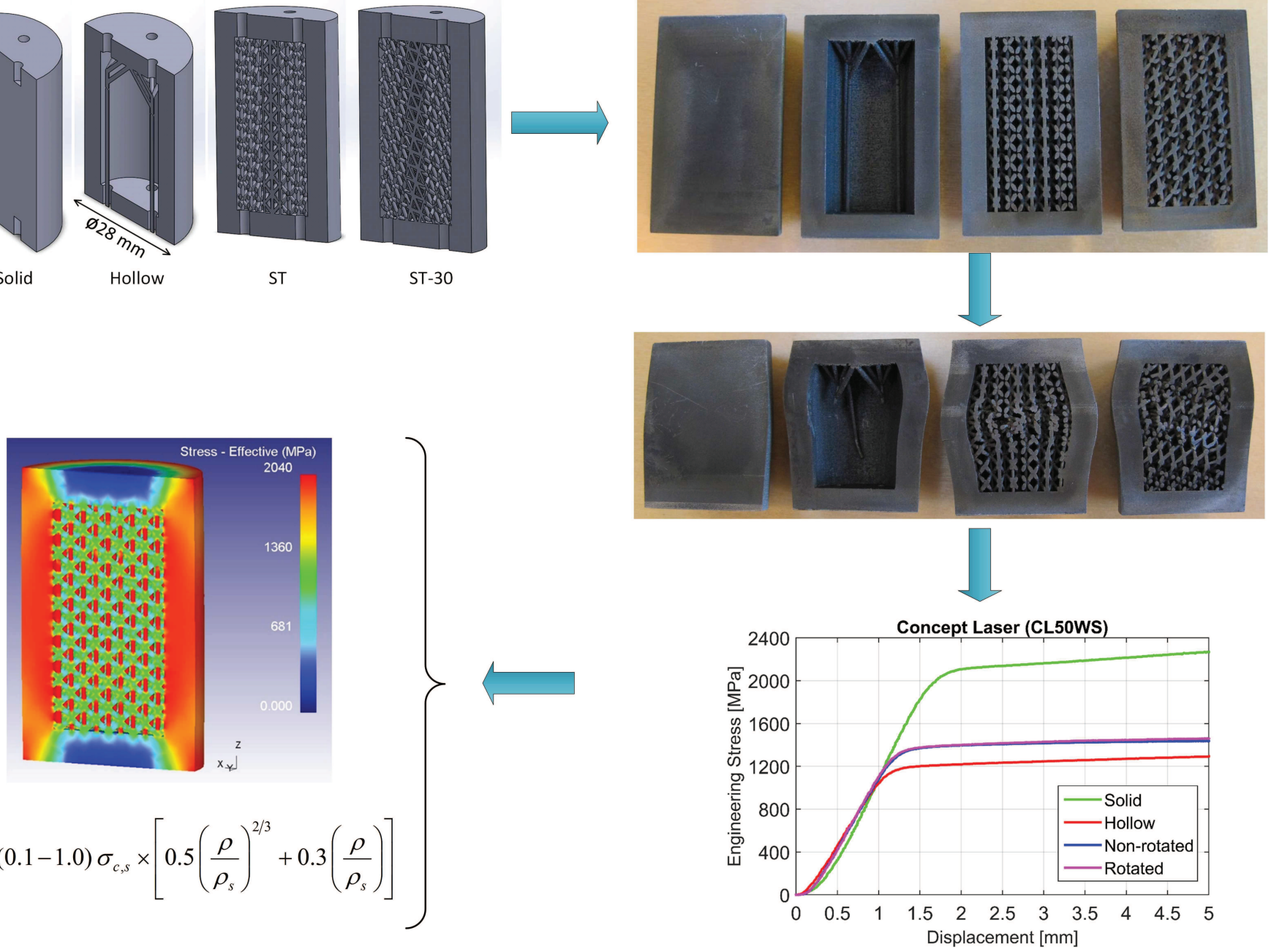


\section{Highlights}

- Selective laser melting systems are able to manufacture mold components using lattice structures.

- Compression test is applied to examine the effect of lattice structures on the strength of new material.

- The collapse strength of cellular lattice structures are compared to solid and hollow specimens.

- The analytical approach includes finite element, geometrical and mathematical models for prediction of collapse strength. 